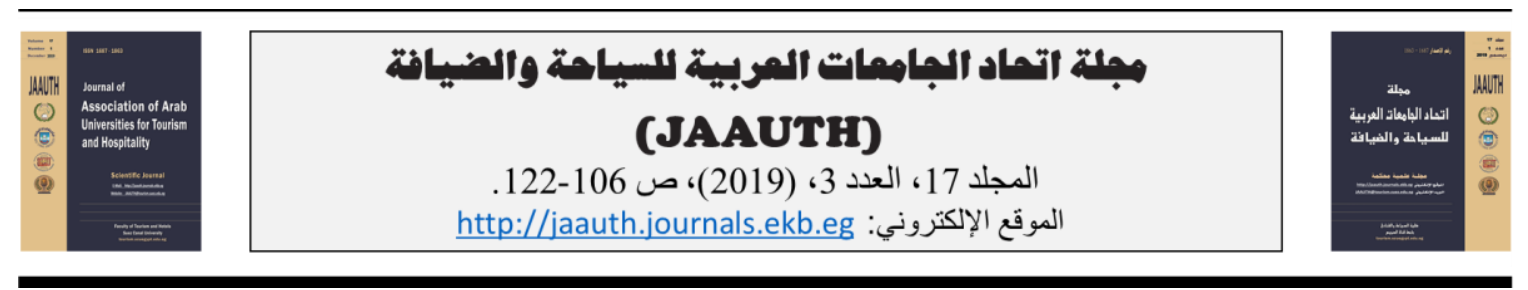

معوقات السياحة الجيولوجية في مصر : بالتطبيق على محمية وادي الجمال

أحمد توفيق سعاد عمران

قسم الدراسات السياحية، كلية السياحة والفنادق، جامعة قناة السويس عمرن

\begin{tabular}{|c|c|}
\hline & مמومات المالة \\
\hline 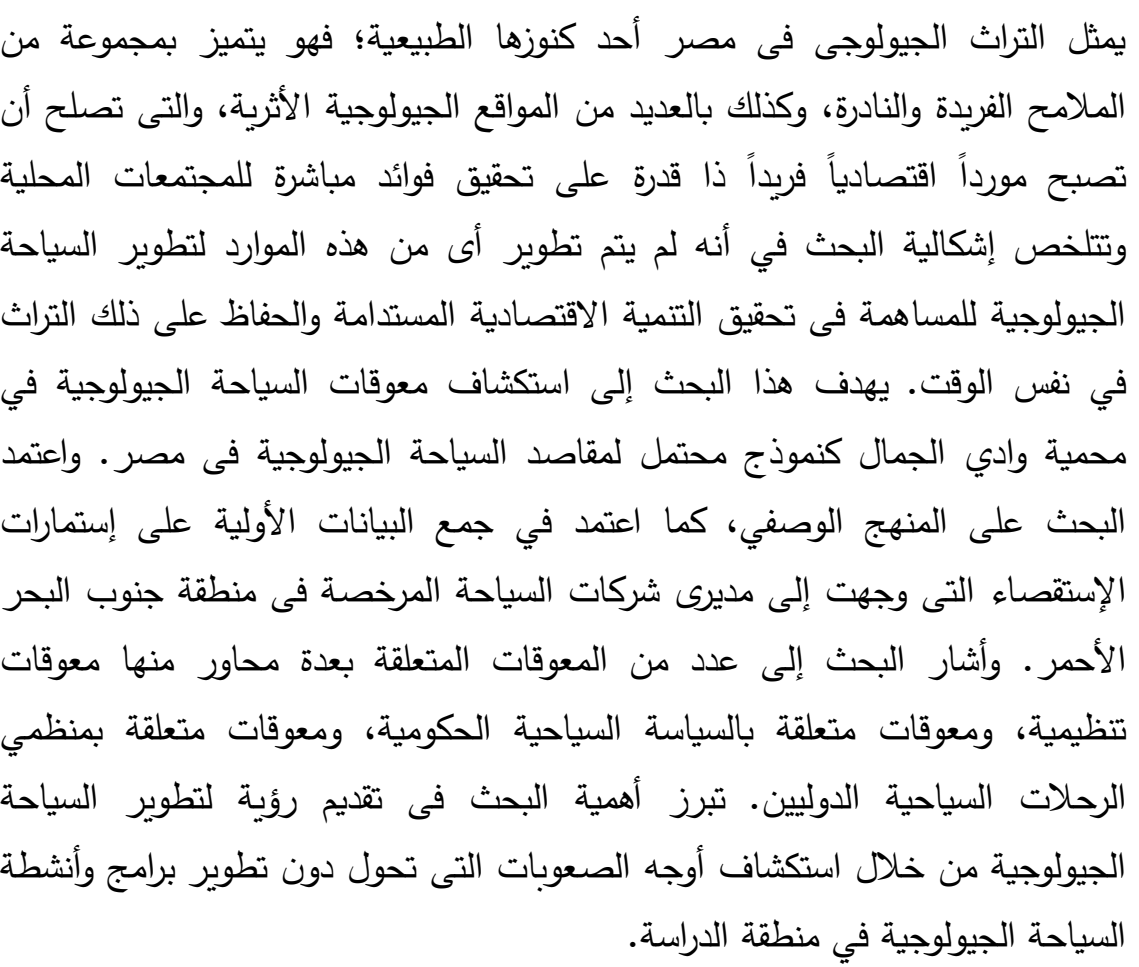 & $\begin{array}{c}\text { (JAAUTH) } \\
\text { (المجلد 17، العدد 3)، (2019)، } 1 \text { (106-123. }\end{array}$ \\
\hline
\end{tabular}

مقدمة

السياحة الجيولوجية هي سياحة مستدامة مع التركيز بشكل أساسي على اختيار السمات الجيولوجية للأرض بطريقة تعزز التفاهم البيئي، وهي مفيدة محليًا (Dowling, 2009).

ويرى Hose (2012) أن السياحة الجيولوجية هي شكل جديد نسبيًا من السياحة القائمة على الجيولوجيا لكنه سريع التطور ، وتمثل شكلًا بديلًا للسياحة، أغراضها الأساسية هي رفع الوعي بأهمية التراث الجيولوجي وتوسيع المعرفة في مجال العلوم الأرضية. وتعد شكلا من أشكال السياحة المتخصصة أو ذات الاهتمامات الخاصة، تعمل على تعزيز الحفاظ على الأرض من خلال إجراءات الاستدامة، ورفع الفهم الجيولوجي من خلال التفسير والتعلم وتولد في النهاية رضا الزائرين.

يشمل نطاق السياحة الجيولوجية مجموعة واسعة من السمات الجيولوجية والجيومرفولوجية. ويركز العنصر الجيولوجي

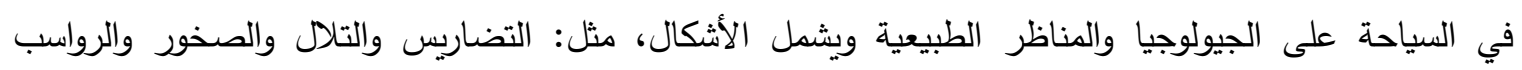


والتربة، وكذلك العمليات مثل: البراكين والترسيب والتعرية، والعنصر السياحي ويشمل: النقل والإقامة والخدمات والتخطيط والإدارة السياحية والأنشطة السياحية(Hose, 2016). ولنين.

المشكلة البحثية مع امتلاك مصر العديد من المواقع الجيولوجية المتميزة والمتتوعة، وتميزها بتراث جيولوجي فريد تؤكده حفريات وادي الحيتان بمحافظة الفيوم، أو كهف سنور بمحافظة بنى سويف، أو قبة الحسنة بمحافظة الجيزة، أو محية وادي الجمال في جنوب الصحراء الشرقية بمحافظة البحر الأحمر والتي تحوي العديد من المواقع الجيولوجية ذات القيمة الجمالية العالية. بالإضافة إلى مناجم الزمرد فى وادي سكيت ومواقع التتقيب عن الذهب في وادي نجرس، الا أنه لم يتم تطوير أى من هذه الموارد لتطوير السياحة الجيولوجية للمساهمة فى تحقيق التتمية الأقتصادية المستامة والحفاظ على ذلك التراث فى نفس الوقت.

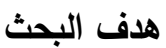

إستكثاف معوقات السياحة الجيولوجية في محمية وادي الجمال كنموذج محتمل لمقاصد السياحة الجيولوجية فى

\section{فرض البحث} توجد علاقة تأثير ذات دلالة احصائية عند مستوى معنوية 0.05 لمعوقات السياحة الجيولوجية في منطقة محمية وادي الجمال علي الوضع الراهن للطلب السياحي على برامج السياحة الجيولوجية في المحمية.

منهجية البحث اعتمدت الدراسة على المنهج الوصفي، وكذلك إجراء الدراسة الميدانية على عينة من مجتمع الدراسة في محاولة للوصول إلي نتائج قابلة للتعميم على ذلك المجتمع، وذلك لفهم و تحليل الدراسة ووصفها وصفاً واقعياً. واستخدم الباحث استمارات الاستقصاء كوسيلة لجمع البيانات.

أولاً: الإطار النظري للبحث

1 ) مفهوم السياحة الجيولوجية

السياحة الجيولوجية هي واحدة من أحدث المفاهيم في الدراسات السياحية اليوم، وترتكز في المقام الأول على تعزيز السمات الجيولوجية والجيومورفولوجية في المناطق الطبيعية كمناطق جذب هئ سياحي. Ólafsdóttir\&) Tverijonaite, 2018)

إن أول تعريف منشور على نطاق واسع للسياحة الجيولوجية ظهر عام 1995م بواسطة Thomas Hose، فى في انجلترا والذي ذكر فيه أن السياحة الجيولوجية" هي توفير التسهيلات التفسيرية والخدمية لتمكين السائحين من اكتساب المعرفة والفهم الجيولوجي والجيومورفولوجي للموقع، بما في ذلك مساهمته في تطوير علوم الأرضيل (Hose,1995). ولقد تم تطوير هذا التعريف عن طريق نفس المؤلف عام 1996 ليكون "توفير التسهيلات والخدمات التفسيرية لتعزيز القيمة والمنفعة الاجتماعية للمواقع الجيولوجية والجيومورفولجية ومواردها لضمان حفظها لاستخدام الطلاب 
والسائحين، وغيرهم من هواة الترفيه (Hose \& Dowling, 2006). ومنذ أول تعريف للسياحة الجيولوجية تتطور هذه الظاهرة بشكل متزايد، وتحصل على شكل من أشكال السياحة المستدامة في العالم) (Hose, 2011) . تدور السياحة الجيولوجية إجمالً حول إنشاء مكان يتمتع فيه كل من السكان المحليين والسائحين بحرية التمتع بالمناظر

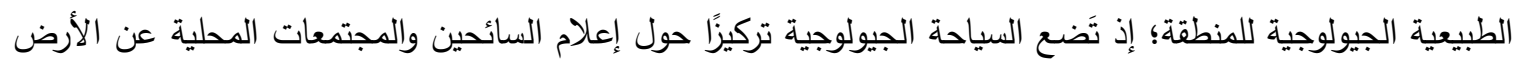
خلال التفسير والتعلم(Newsome\& Johnson, 2013) . ووفقا لجمعية ناشيونال جيوغرافيك، فإنَّ السياحة الجيولوجية تتميز بسمات ممثلة بنزاهة المكان، والرموز الدولية، وانتقائية السوق والتنوع، والرضا السياحي، ومشاركة المجتمع المحلي، والمنفعة، وحماية وتعزيز جاذبية الوجهة، واستخدام الأراضي والتخطيط، وحفظ الموارد، التفسير والتقييم التفاعلي .(National Geographic Society, 2009)

2) الأبعاد المختلفة السياحة للجيولوجية: إنَّ تعزيز فهم السياحة الجيولوجية والفوائد التي تولدها للمجتمع له دور أساسي في الحصول على اعتراف واسع لدعم

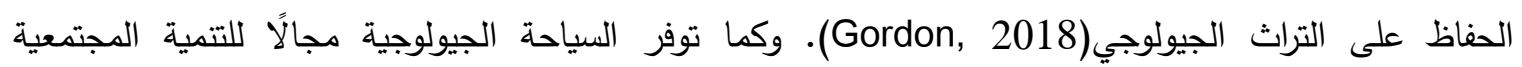
والإقليمية للعديد من الأماكن حول العالم؛ فإنَّها تتطوي على العديد من الأبعاد:

1-2

تشكل السياحة الجيولوجية أداة لإدارة التراث الجيولوجي مما يحقق التوازن بين النمو الاقتصادي والحفاظ على الموارد الطبيعية، وهو جوهر الهدف من التتمية المستدامة الذي يستدعي إدارة الموارد وضمان جودتها ووفرتها على المدى لطى لئى الطويل (Ehsan, Leman,\& Ara Begum, 2013).

ويرى Dowling (2013) أنه يمكن النظر إلى السياحة الجيولوجية على أنَّها طريقة مبتكره يمكن من خلالها الحفاظ على المواقع الجيولوجية، وذلك من خلال السكان المحليين، وأصحاب المصلحة الآخرين؛ حيث تصبح الجيولوجيا محور التركيز، وذلك يتحقق من خلال تحقيق المنافع الثخصية والمادية عن طريق السياحة الجيولوجية.

2-2

تعزز السياحة الجيولوجية رفاهية المجتمع المحلي المتاخم للمواقع الجيولوجية بشكل عام؛ حيث تطبق مفاهيم

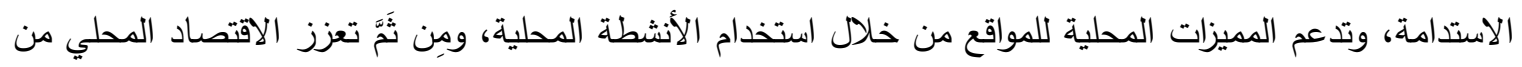

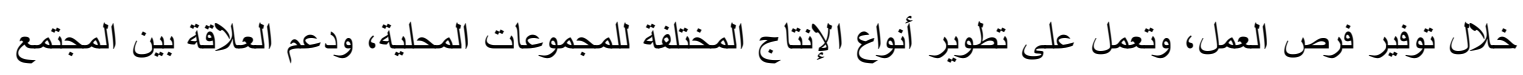
المحلي والأرض التي يعيشون عليها (Allan, 2013).

إن السياحة الجيولوجية من المكن أن تؤدي دورا كبيرا في التتمية المحلية، إذ إنَّ نجاحها على المدى الطويل يعتمد على خلق حوافز محلية للحفاظ على التراث الجيولوجي، وتضمين المجتمع المضيف من خلال مجموعات أصحاب دوني المصلحة، وتثمل هذه المجموعات صناع السياحة، والمخططين، والمستثرين، والمنظمات غير ونصئ الحكومية،

والمجتمعات المحلية، والسائحين (Dowling, 2009). 
3-2

تعتبر السياحة الجيولوجية إستراتيجية فعالة للتمية المستدامة داخل المناطق النائية؛ إذ إنَّها تستهلك موارد أقل من

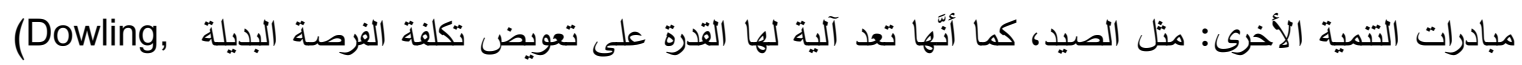

يرى كل منFarsani, Coelho,\& Costa (2012) أن تطوير السياحة الجيولوجية يزيد الفوائد الاقتصادية لصناعة السياحة، ويدفع التتمية الاقتصادية في المناطق المتاخمة للمواقع الجيولوجية، فهناك على سبيل المثال أكثر من نـ 5000 كهف عرض في جميع أنحاء العالم تجلب أكثر من 2 مليار دولار سنويا وتوفر 200000 فرصة عمل مباشرة سنويا.

يؤكد Hose (2011) على قدرة السياحة الجيولوجية على تمديد الموسم السياحي وتعزيز الاقتصاد المحلي، وتوفير فرص عمل إضافية داخل المناطق المشاركة. وتتمثل فرص زيادة الدخل المحلي من السياحة الجيولوجية في التوظيف المباشر والعمالة غير المباشرة والعمالة الناتجة عن زيادة قدرة السكان المحليين على الإنفاق، وكذلك يُنْهر تطوير السياحة الجيولوجية في تطوير البيئة التحتية.

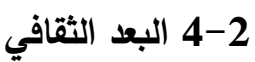
إن تعزيز السياحة الجيولوجية يؤدي إلى إنعاش الثقافة التقليدية وتقليل الآثار الثقافية السلبية للسياحة الجماعية؛ إذ تعمل السياحة الجيولوجية على تقديم المجتمع المحلي المضيف للسائحين من خلال عرض المنتجات المناتيز المحلية والحرف اليدوية. وهي تعزز الأنشطة الإقليمية للأغذية والحرف، وتؤدي دورا في تعزيز المطعم المحلي والحرف عندي اليدوية كمنتجات ثقافية عن طريق المهرجانات والمعارض (Farsani, Coelho, \& Costa, 2012). يوضح Dowling (2009) أنَّ السياحة الجيولوجية تُنهم بشكل كبير في زيادة الوعي بقيمة التراث الجيولوجي، وتمكن المجتمع المحلي من تحقيق فوائد من التراث الجيولوجي، ما يشكل دافعا قويا لحماية ذلك التراث.

3) تحديات السياحة الجيولوجية يذكر Hose (2006) أن السياحة العالمية تواجه العديد من التحديات أهمها عدم وجو تعريف مقبول عالميا للسياحة الجيولوجية. وكذلك تعاني السمات اللأحيائية مثل نظيراتها الحيوية من الاثار الضارة للنشاط الإنسانى حيث تتأثر المناظر الطبيعية والصخور والحفريات جميعا بشكل سلبي من النشاط السياحي، وأخيرا هناك تحدى اخر هو إدرة التراث الجيولوجى فيما يتعلق بقضايا التعليم والتقسيروالتتمية المستدامة.

وفى دراسة حول تحديات السياحة الجيولوجية في محمية وادى الريان كنموذج محتمل للسياحة الجيولوجية في مصر أكد Kamel, Hassan, \& Wafik (2018) أن التحدي الرئيسي الذي يواجه السياحة الجيولوجية في وادي الحيتان هو أن مفهوم السياحة الجيولوجية لا يزال غير واضح للجمهور ، كما أن هناك نقص في الوعي بتعريف السياحة الجيولوجية، و خلط بين السياحة الجيولوجية والسياحة البيئية، كما تعانى من عدم وجود دليل للسائحين الجيولوجيين، وعدم توافر المعلومات التفسيرية، وعدم وجود منشورات وكتيبات بلغات مختلفة. وذكرت النتائج أيضا أن هناك نقص وجن 
في توافر خدمات الطعام والثراب المتاحة للزائرين، وكذلك كان الافتقار إلى الثعور بالأمان والسلامة من أهم العقبات التي تواجه السياحة الجيولوجية في وادي الحيتان.

4) منطقة الاراسة وادي الجمال أحد أودية البحر الأحمر الثهيرة، ويعد واحدًا من أهم أحواض الصحراء الثرقية، وهو ثالث أكبر وديانها

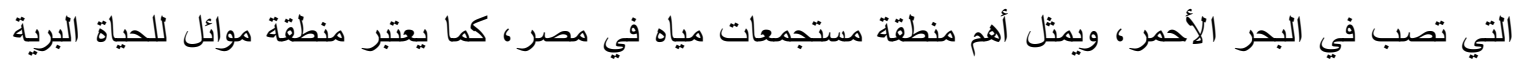

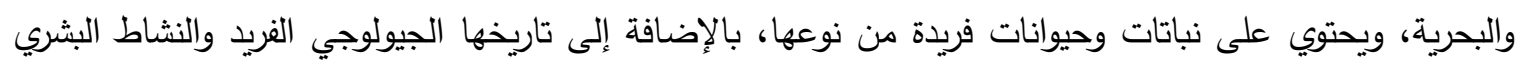

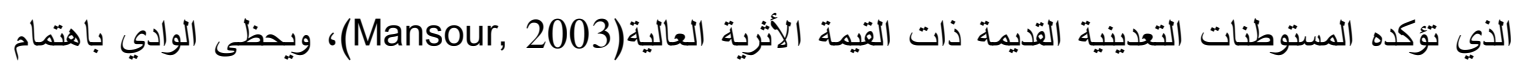

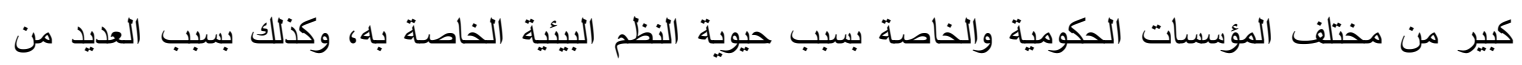
المواقع الأثرية داخل هذا القطاع (Tourism Development Authority, 2003).

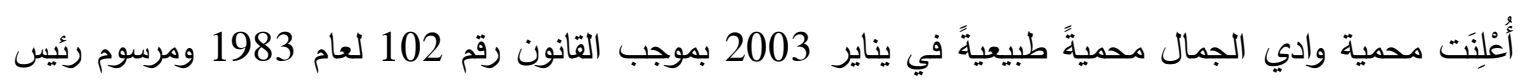

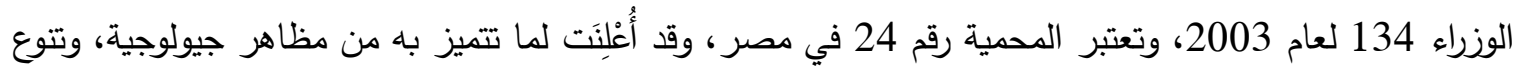

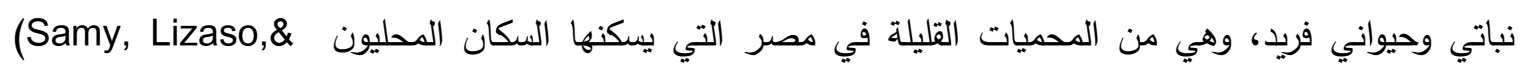

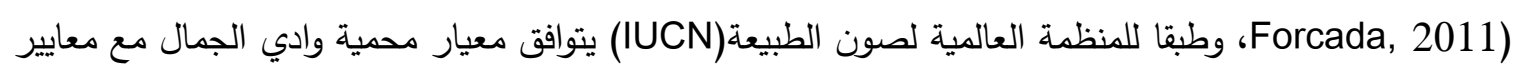

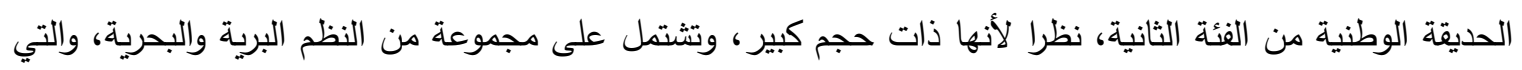
لم يتم تغيرها بشكل كبير، ولها مميزات المناظر الطبيعية المذهلة (TDA, 2003).

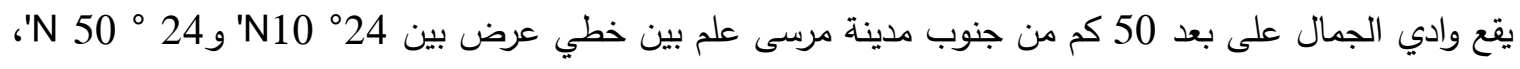

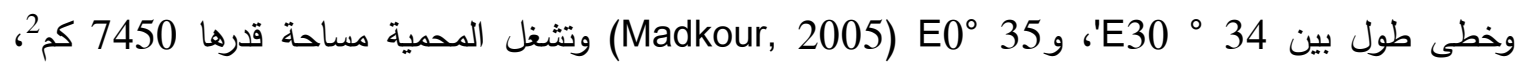

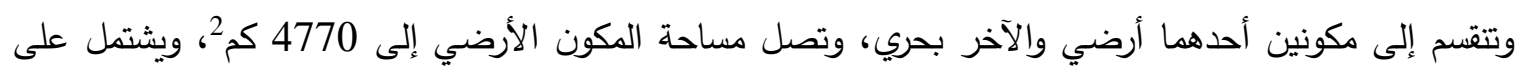

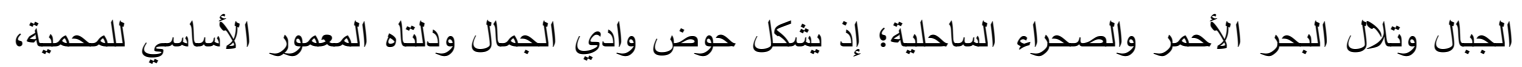

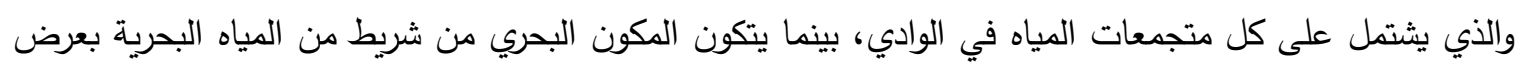

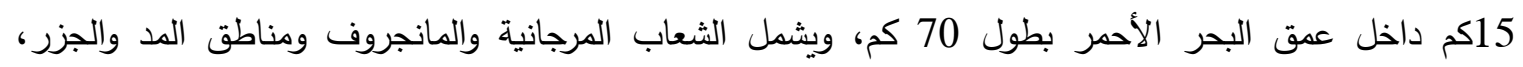
والجزر البحرية وتبلغ مساحته 2000 كم² تقريبا (El-Regal, 2014). 


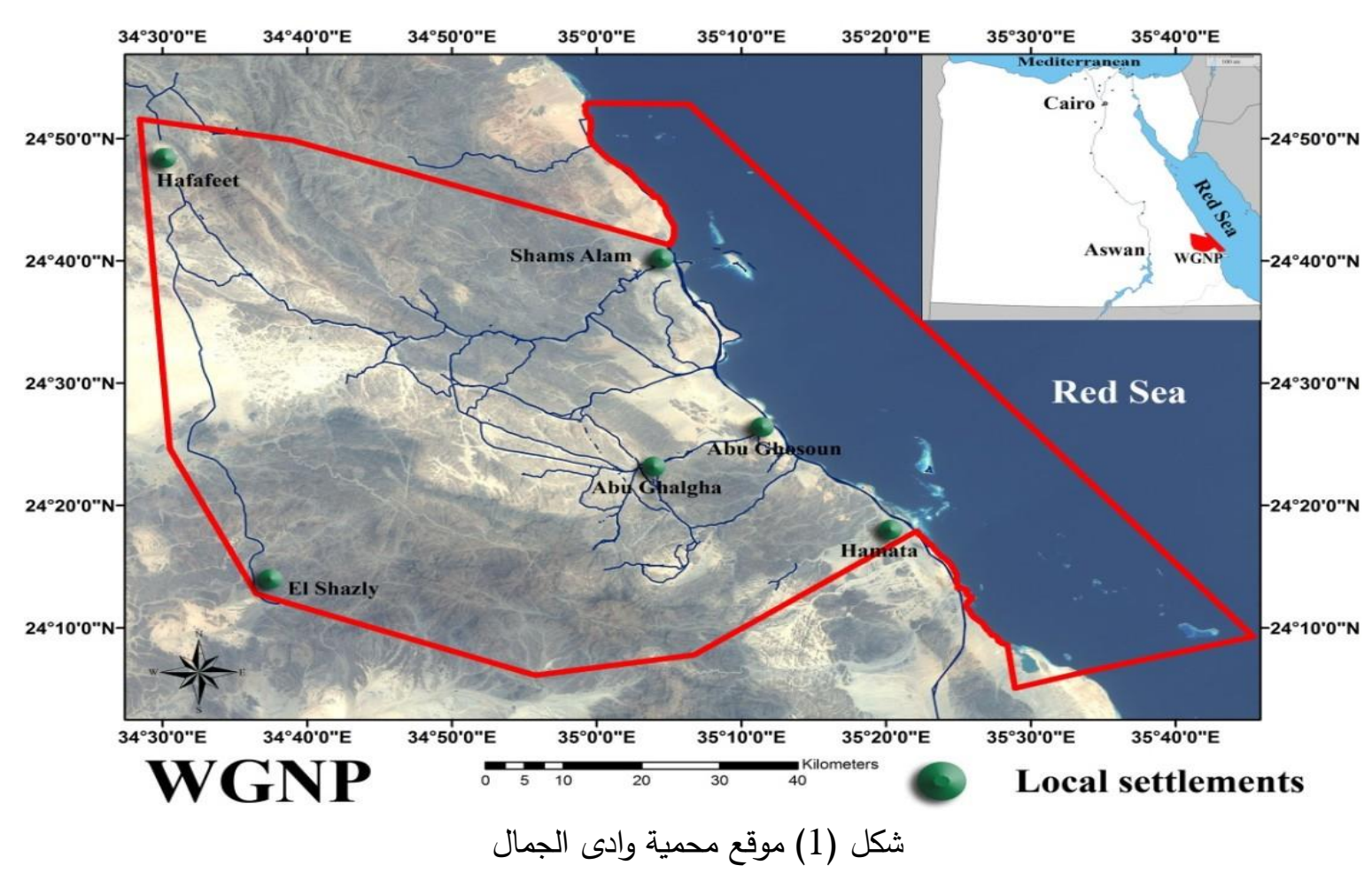

5) الظروف الجيولوجية والتضاريسية

(El-Rahmany et al,. يعتبر حوض وادي الجمال أحد المعالم الجيولوجية البارزة في الصحراء الثرقية في مصر (2015 كما تعتبر جيولوجية وادي الجمال فريدة من نوعها لعدة أسباب؛ حيث تحتوي التكوينات الجيولوجية على بعض أقدم الصخور على وجه الأرض (ما قبل الكامري) ومِن ثم فإن المنطقة لديها قصة رائعة حول الطرق التي

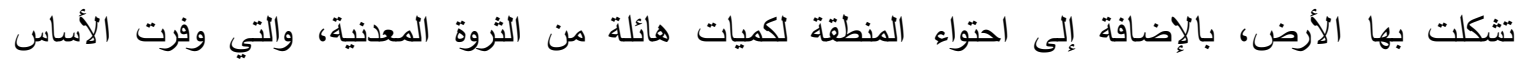
للمستوطنات البشرية التي عاشت هناك منذ القدم، وأخيرا فإن التكوينات الجيولوجية قد صنعت أشكالا أرضية مميزة صاحبتها مناظر طبيعية خلابة) (TDA, 2003) .

6) أدت الاستكثافات الجيولوجية التي قام بها الرومان والبطالمة إلى اكتشاف كميات وأنواع كبيرة من المعادن في وادي الجمال؛ إذ يقع أقدم مناجم الزمرد في العالم، وتم استخراج الزمرد من المنطقة على نطاق واسع لمدة تقرب من الألف عام. ولقد أسفرت عمليات التعدين عن إنشاء بلدات كان يعمل بها مئات من العمال في بناء وتثغيل المناجم وعملية التصنيع، ولقد تم إنشاء العديد من التحصينات للدفاع عن هذه البلدان.. Harrell, 2004) . إنَّ البقايا الهيكلية للعديد من مراكز الحراسة والقلاع تقدم دليلا حيا على أنَّ تلك المنطقة قد تم تأمينها من قبل عدد كبير من الحراس، كما توضح وفرة البقايا الفخارية والمنحوتات الحجرية والأدوات دليلًا وافيًا على الحجم الكبير للمستوطنات البشرية التي ازدهرت في تلك المنطقة. ولقد سجلت المسوحات الأثرية التي أجريت منذ عام 1991 في المحيط المباشر للدمية 38 موقعا أثريَّا يتراوح تاريخها بين البطالمة إلى المواقع الإسلامية، وتشمل هذه المواقع

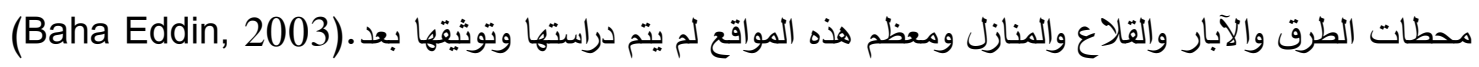




\section{7}

كانت محمية وادي الجمال منذ إنثائها عام 2003 محورا للعديد من مشروعات خطط الجمال الإدارة الوطنية والدولية، وتم

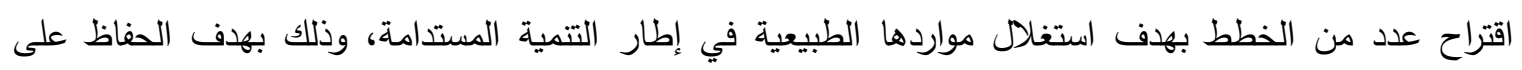

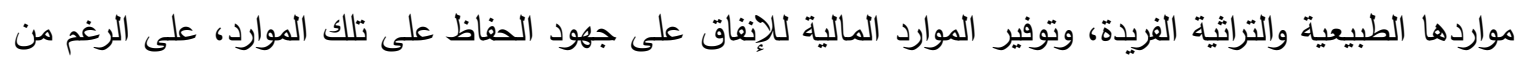

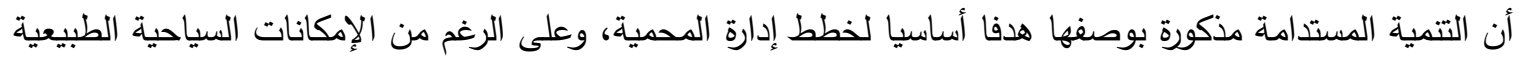

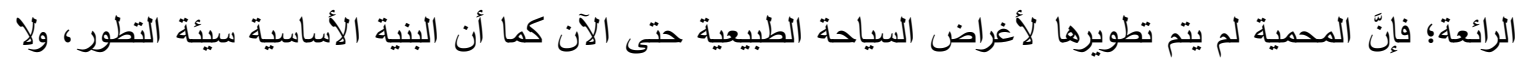

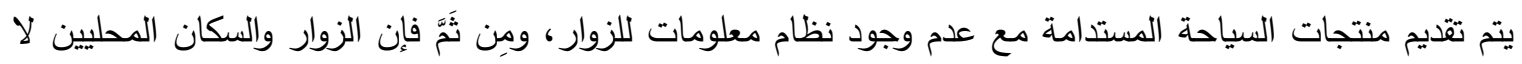
يدركون أنَّم يزورون محمية طبيعية، (Sarhan, 2016) ثانيا الاراسة الميدانية

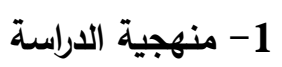

اعتدت الدراسة على المنهج الوصفي التحليلي من خلال جمع المعلومات وتحليلها عن تطوير السياحة الجيولوجية

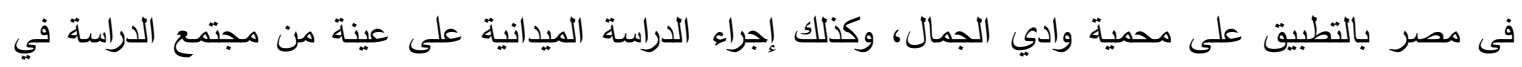

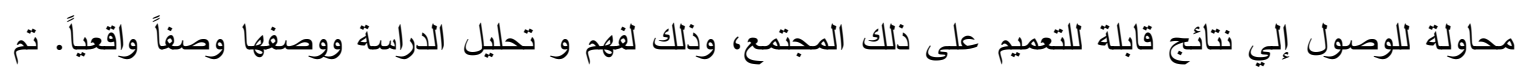
وضع فرضية البحث بناء على مشكلة وتساؤلات الدراسة وذلك من أجل تحقيق أهداف الدراسة المرجوة التي سيتم إختبارها:

• ثوجد علاقة تأثير ذات دلالة احصائية عند مستوى معنوية 0.05 لمعوقات السياحة الجيولوجية في منطقة محمية وادي الجمال علي الوضع الراهن للطلب السياحي على برامج السياحة الجيولوجية في الدحمية.

2- مجتمع وعينة الدراسة

يتكون مجتمع الدراسة من مديري شركات السياحة في مرسي علم حيث بلغ عدد شركات السياحة العاملة فى المنطقة

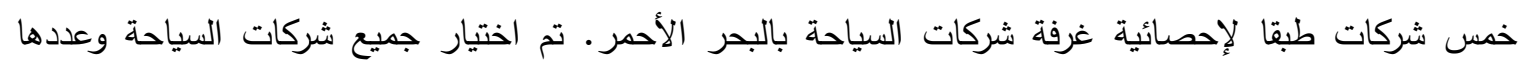
خمس، اعتمدت الدراسة الحالية على استمارة الاستقصاء كأداة لجمع البيانات.

3- 3 المناقشة والنتائج:

أولا: تحليل ومناقثة البيانات الايموجرافية

من خلال جمع الاستمارات التي تم توزيعها على مديري الثركات السياحية عينة الدراسة، تضم البيانات الثخصية وظيفة الدديرين. يوضح جدول رقم (1) تحليل نتائج البيانات الثخصية كالتالي: 
جدول (1) تحليل البيانات الثخصية للمديرين

\begin{tabular}{|c|c|c|c|c|}
\hline \multirow[t]{2}{*}{ الترتيب } & \multicolumn{2}{|c|}{ التكرارات والنسب المئوية } & \multirow{2}{*}{\multicolumn{2}{|c|}{ الـمتـغيز }} \\
\hline & $\%$ & ت & & \\
\hline 1 & 56.8 & 21 & تسويق سياحي & \multirow{5}{*}{ الوظيفة } \\
\hline 2 & 29.7 & 11 & مدير سياحة & \\
\hline 3 & 8.1 & 3 & مدير فرع & \\
\hline 4 & 2.7 & 1 & خدمة عملاء & \\
\hline 5 & 2.7 & 1 & مدير تشغيل & \\
\hline \multicolumn{2}{|c|}{$\% 100$} & 37 & \multicolumn{2}{|c|}{ المجموع } \\
\hline
\end{tabular}

يوضح الجدول رقم (1) توزيع المبحوثين وفقا لمتغير الوظيفة حيث يعمل أغلب أفراد عينة الدراسة في التسويق السياحي بنسبة 56.8 \% و يليهم مديري قسم السياحة بنسبة 29.7\% و مديري الفروع بنسبة 8.1 \%و أخيرا مسئولي خدمة العملاء ومدير التثغيل بنفس النسبة 2.7\% ثانيا: تحليل نتائج الأسئلة الموضوعية

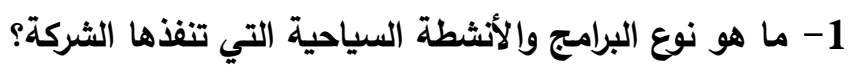
يهدف السؤال لمعرفة نوع البرامج والأنشطة السياحية التي تتفذها الشركة. جدول (2) يوضح الاجابة على هذا التساؤل: جدول (2) نوع البرامج والأنشطة السياحية التي تتفذها الشركة

\begin{tabular}{|c|c|c|c|}
\hline \multicolumn{2}{|c|}{ متولوجة } & \multicolumn{2}{|c|}{} \\
\hline$\%$ & $ت$ & $\%$ & 3 \\
\hline 8.1 & 3 & 91.9 & 34 \\
\hline
\end{tabular}

تبين من الجدول (2) بالنسبة لإجابات المديرين أن (91.9\%) من الشركات تتظم برامج سياحية متتوعة، بينما أكد

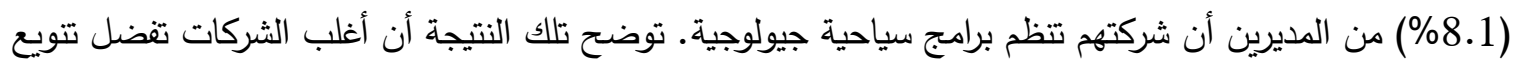
برامجها عن التخصص بنمط سياحي محدد مثل السياحة الجيولوجية. ثالثا تحليل العبارات التوضيحية ويشمل ذلك الجزء مجموعة من المحاور التي بها مجموعة العبارات التي يمكن من خلالها الاجابة على تساؤلات الدراسة. تلك المحاور على النحو التالي: - - الوضع الراهن للطلب السياحي على برامج السياحة الجيولوجية - - معوقات خاصة بالمواقع الجيولوجية

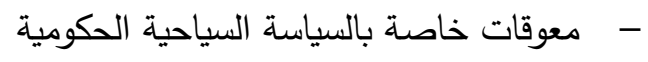
- معوقات خاصة بمنظمى البرامج السياحية الدولية

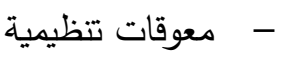


من خلال جمع الاستمارات التي تم توزيعها على أفراد عينة الدراسة من المديرين بالثركات السياحية عينة الدراسة تم

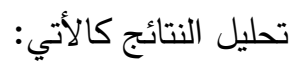

\section{1. محور الوضع الراهن للطلب السياحي على برامج السياحة الجيولوجية}

يهدف هذا المحور لمعرفة الوضع الراهن للطلب السياحي على برامج السياحة الجيولوجية بمحمية وادي الجمال عينة الدراسة. جدول (3) إجابات يوضح إجابات المديرين على عبارات هذا المحور علي النحو التالي:

جدول رقم (3) الوضع الراهن للطلب السياحي على برامج السياحة الجيولوجية بمحية وادي الجمال

\begin{tabular}{|c|c|c|c|c|c|c|c|c|c|c|}
\hline \multirow[b]{2}{*}{ 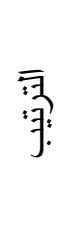 } & \multicolumn{2}{|c|}{ المؤشرات الإحصائية } & \multicolumn{5}{|c|}{ درجة التكرار والنسبة المئوية } & \multirow{2}{*}{\multicolumn{2}{|c|}{$\bar{q}$}} & \multirow[b]{2}{*}{ r } \\
\hline & المعيـــاري & 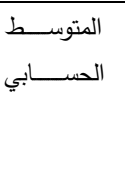 & موافق & موافق & 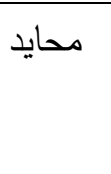 & موافق & بشدة & & & \\
\hline \multirow[t]{2}{*}{2} & \multirow{2}{*}{.608} & \multirow[t]{2}{*}{4.73} & 29 & 7 & 0 & 1 & 0 & ك & \multirow{2}{*}{ بتر بتسم الطلب السياحة الجيولي علية } & \multirow[b]{2}{*}{1} \\
\hline & & & 78.4 & 18.9 & 0 & 2.7 & 0 & $\%$ & & \\
\hline \multirow[t]{2}{*}{1} & \multirow{2}{*}{.417} & \multirow[t]{2}{*}{4.78} & 29 & 8 & 0 & 0 & 0 & 5 & \multirow{2}{*}{ بالغطس النية هي الأنشي تلك المرتبطة الأنشطة } & \multirow[b]{2}{*}{2} \\
\hline & & & 78.4 & 21.6 & 0 & 0 & 0 & $\%$ & & \\
\hline \multirow[t]{2}{*}{3} & \multirow[t]{2}{*}{.686} & \multirow[t]{2}{*}{4.59} & 26 & 7 & 4 & 0 & 0 & S & \multirow{2}{*}{ 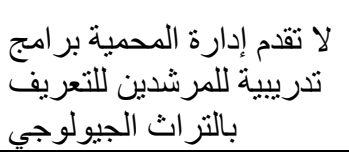 } & \multirow[b]{2}{*}{3} \\
\hline & & & 70.3 & 18.9 & 10.8 & 0 & 0 & $\%$ & & \\
\hline \multirow[t]{2}{*}{4} & \multirow{2}{*}{.837} & \multirow[t]{2}{*}{4.51} & 25 & 8 & 2 & 2 & 0 & S & \multirow{2}{*}{ 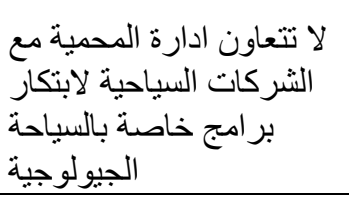 } & \multirow[b]{2}{*}{4} \\
\hline & & & 67.6 & 21.6 & 5.4 & 5.4 & 0 & $\%$ & & \\
\hline \multirow[t]{2}{*}{5} & \multirow[t]{2}{*}{.901} & \multirow[t]{2}{*}{4.49} & 26 & 5 & 4 & 2 & 0 & 5 & \multirow{2}{*}{ 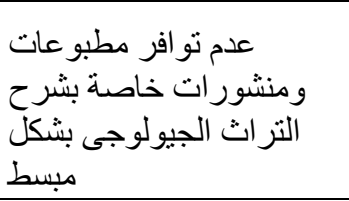 } & \multirow[b]{2}{*}{5} \\
\hline & & & 70.3 & 13.5 & 10.8 & 5.4 & 0 & $\%$ & & \\
\hline- & 0.689 & 4.62 & & & & للـــــــــ & ع & سـ & الـــــــت & \\
\hline
\end{tabular}

تم إستخدام جداول التكرار الإحصائية لوصف المؤشرات الأساسية للبيانات بواسطة النسب المئوية. كما إستخدم المتوسط الحسابي لإستخراج متوسط الترتيب لكل عبارة من عبارات محور الوضع الراهن للطلب السياحي على برامج السياحة الجيولوجية بمحمية وادي الجمال.

يتضح من النتائج أن أفراد عينة الدراسة وافقوا بشدة على أن النمط السائد من الأنشطة السياحية في منطقة الدراسة هي تللك المرتبطة بالغطس والأنشطة الثاطئية." بمتوسط حسابي (4.78) وكذلك على أن الطلب السياحي على برامج السياحة الجيولوجية يتسم بالضعف والموسمية " بمتوسط حسابي (4.73) , وأن إدارة المحمية لا تقدم برامج تدريبية للمرشدين للتعريف بالتراث الجيولوجى " بمتوسط حسابي (4.59 ولا تتعاون مع الثركات السياحية لابتكار 
برامج خاصة بالسياحة الجيولوجية " بمتوسط حسابي (4.51 ولا توفر مطبوعات ومنشورات خاصة بشرح التراث الجيولوجى بشكل مبسط " بمتوسط حسابي (4.49).

2- محور المعوقات الخاصة بالمواقع الجيولوجية

يهدف هذا المحور لمعرفة المعوقات الخاصة بالمواقع الجيولوجية بمحمية وادي الجمال عينة الدراسة. جدول (4) إجابات يوضح إجابات المديرين على عبارات هذا المحور على النحو التالي: جدول (4) المعوقات الخاصة بالمواقع الجيولوجية

\begin{tabular}{|c|c|c|c|c|c|c|c|c|c|c|}
\hline \multirow{2}{*}{ 司 } & \multicolumn{2}{|c|}{ المؤشرات الإحصائية } & \multicolumn{5}{|c|}{ درجة التكرار والنسبة المئوية } & \multirow{2}{*}{\multicolumn{2}{|c|}{ 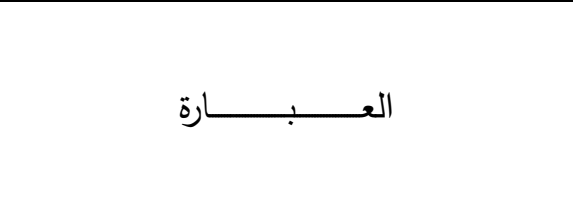 }} & \multirow{2}{*}{ 5 } \\
\hline & 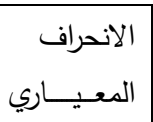 & 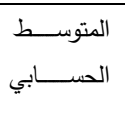 & بشدة & مو افق & محايد & 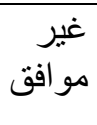 & بثيرة موافق & & & \\
\hline \multirow[t]{2}{*}{7} & \multirow[t]{2}{*}{.800} & \multirow[t]{2}{*}{4.16} & 14 & 16 & 6 & 1 & 0 & ك & \multirow{2}{*}{ الجيولوجية الداخلية الوصول إلى المواقع } & \multirow[b]{2}{*}{1} \\
\hline & & & 37.8 & 43.2 & 16.2 & 2.7 & 0 & $\%$ & & \\
\hline \multirow[t]{2}{*}{4} & \multirow[t]{2}{*}{.740} & \multirow[t]{2}{*}{4.30} & 17 & 14 & 6 & 0 & 0 & ك & \multirow{2}{*}{ 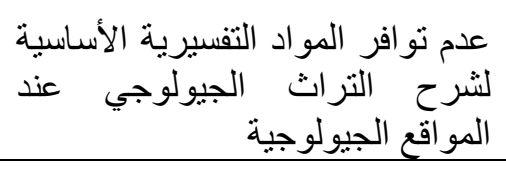 } & \\
\hline & & & 45.9 & 37.8 & 16.2 & 0 & 0 & $\%$ & & 2 \\
\hline \multirow[t]{2}{*}{3} & \multirow[t]{2}{*}{.893} & \multirow[t]{2}{*}{4.38} & 20 & 14 & 1 & 1 & 1 & ك & \multirow{2}{*}{ بتحدثون توافر مرشات المختلفين جيولوجيين } & \multirow[b]{2}{*}{3} \\
\hline & & & 54.1 & 37.8 & 2.7 & 2.7 & 2.7 & $\%$ & & \\
\hline \multirow[t]{2}{*}{5} & \multirow[t]{2}{*}{.740} & \multirow[t]{2}{*}{4.30} & 17 & 14 & 6 & 0 & 0 & ك & \multirow{2}{*}{ |المحليين الأدلاء ذوى الخبرة من السكان } & \multirow[b]{2}{*}{4} \\
\hline & & & 45.9 & 37.8 & 16.2 & 0 & 0 & $\%$ & & \\
\hline \multirow[t]{2}{*}{1} & \multirow[t]{2}{*}{.607} & \multirow[t]{2}{*}{4.51} & 21 & 14 & 2 & 0 & 0 & ك & \multirow{2}{*}{ ندرة المنشورات و الأبحاث العمية } & \multirow[b]{2}{*}{5} \\
\hline & & & 56.8 & 37.8 & 5.4 & 0 & 0 & $\%$ & & \\
\hline \multirow[t]{2}{*}{2} & \multirow[t]{2}{*}{.762} & \multirow[t]{2}{*}{4.41} & 20 & 13 & 3 & 1 & 0 & ك & \multirow{2}{*}{ 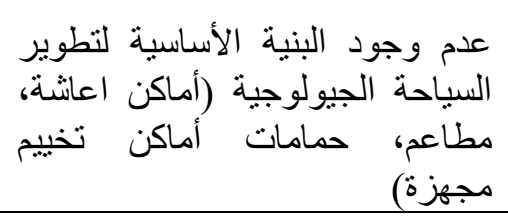 } & \multirow[b]{2}{*}{6} \\
\hline & & & 54.1 & 35.1 & 8.1 & 2.7 & 0 & $\%$ & & \\
\hline 6 & .777 & 4.30 & 17 & 15 & 4 & 1 & 0 & ك & انتشار عمليات التعدين داخل المحمية & \\
\hline & & & 45.9 & 40.5 & 10.8 & 2.7 & 0 & $\%$ & & 7 \\
\hline 8 & .983 & 3.92 & 12 & 13 & 10 & 1 & 1 & ك & عدم وجود منتجات سياحية & \\
\hline & & & 32.4 & 35.1 & 27 & 2.7 & 2.7 & $\%$ & 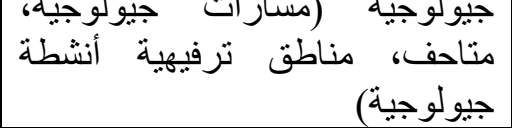 & 8 \\
\hline- & 0.787 & 4.29 & & & & & & & 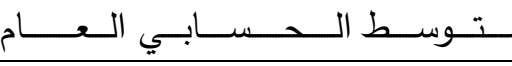 & \\
\hline
\end{tabular}


توضح النتائج أن عينة الدراسة قد وافقت على أن أهم المعوقات التى ترتبط بالمواقع الجيولوجية نفسها هى ندرة الأبحاث العلمية حول التراث الجيولوجى فى منطقة الدراسة " بمتوسط حسابي (4.51), و عدم وجود البنية الأساسية لتطوير السياحة الجيولوجية (أماكن اعاشة،مطاعم ،حمامات،أماكن تخييم مجهزة)" بمتوسط حسابي (4.41), وعدم توافر مرشدين جيولوجيين يتحدثون اللغات المختلفة " بمتوسط حسابي (4.38), وعدم توافر المواد التفسيرية الأساسية لشرح التراث الجيولوجى عند المواقع الجيولوجية " بمتوسط حسابي (4.30), انتثار عمليات التعدين داخل المحمية بدون تمييزوبشكل عشوائى " بمتوسط حسابي (4.30)

3-محور المعوقات الخاصة بالسياسة السياحية الحكومية يهدف هذا المحور لمعرفة المعوقات الخاصة بالسياسة السياحية الحكومية. جدول (5) إجابات يوضح إجابات المديرين على عبارات هذا المحور على النحو التالي: لئل

جدول (5) المعوقات الخاصة بالسياسة السياحية الحكومية

\begin{tabular}{|c|c|c|c|c|c|c|c|c|c|c|}
\hline \multirow{2}{*}{ الترت } & \multicolumn{2}{|c|}{ المؤشرات الإحصائية } & \multicolumn{5}{|c|}{ درجة التكرار والنسبة المئوية } & \multirow{2}{*}{\multicolumn{2}{|c|}{ العــــــــــــــــــارة }} & \multirow[b]{2}{*}{ r } \\
\hline & المعيــاري & 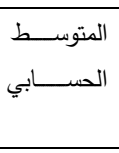 & 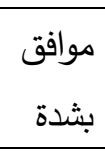 & موافق & محايد & 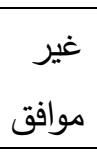 & بشدة موافق & & & \\
\hline \multirow[t]{2}{*}{1} & \multirow[t]{2}{*}{.605} & \multirow[t]{2}{*}{4.46} & 19 & 16 & 2 & 0 & 0 & & \multirow{2}{*}{ التسوكيز لأنماط السياحة الثناطئية النياحي على } & \\
\hline & & & 51.4 & 43.2 & 5.4 & 0 & 0 & $\%$ & & 1 \\
\hline \multirow[t]{2}{*}{3} & \multirow[t]{2}{*}{.798} & \multirow[t]{2}{*}{4.41} & 21 & 11 & 4 & 1 & 0 & ك & \multirow{2}{*}{ في أنماط سياحية مستحدثة التجية لتجيع الاستتمار } & \multirow[b]{2}{*}{2} \\
\hline & & & 56.8 & 29.7 & 10.8 & 2.7 & 0 & $\%$ & & \\
\hline \multirow[t]{2}{*}{2} & \multirow[t]{2}{*}{.691} & \multirow[t]{2}{*}{4.46} & 20 & 15 & 1 & 1 & 0 & 5 & \multirow{2}{*}{ 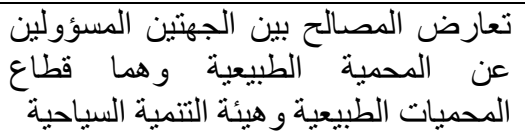 } & \multirow[b]{2}{*}{3} \\
\hline & & & 54.1 & 40.5 & 2.7 & 2.7 & 0 & $\%$ & & \\
\hline \multirow[t]{2}{*}{7} & \multirow[t]{2}{*}{.918} & \multirow[t]{2}{*}{4.14} & 15 & 15 & 4 & 3 & 0 & كs & \multirow{2}{*}{ الخاصنمع التوافق بين أصحاب المصلى و الحكومة و الجهات من } & \multirow[b]{2}{*}{4} \\
\hline & & & 40.5 & 40.5 & 10.8 & 8.1 & 0 & $\%$ & & \\
\hline \multirow[t]{2}{*}{4} & \multirow[t]{2}{*}{.857} & \multirow[t]{2}{*}{4.35} & 19 & 14 & 3 & 0 & 1 & 5) & \multirow{2}{*}{ 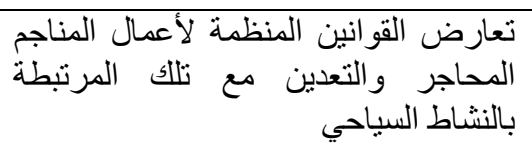 } & \multirow[b]{2}{*}{5} \\
\hline & & & 51.4 & 37.8 & 8.1 & 0 & 2.7 & $\%$ & & \\
\hline \multirow[t]{2}{*}{5} & \multirow[t]{2}{*}{.669} & \multirow{2}{*}{4.32} & 16 & 17 & 4 & 0 & 0 & ك & \multirow{2}{*}{ الجمال بأعمال التعدين داخل محمية وادي } & \multirow[b]{2}{*}{6} \\
\hline & & & 43.2 & 45.9 & 10.8 & 0 & 0 & $\%$ & & \\
\hline \multirow[t]{2}{*}{6} & .740 & 4.30 & 16 & 17 & 3 & 1 & 0 & ك5 & قصور البرامج الإعلامية المناسبة & \\
\hline & & & 43.2 & 45.9 & 8.1 & 2.7 & 0 & $\%$ & & \\
\hline- & 0.754 & 4.35 & & & الــ & & & & 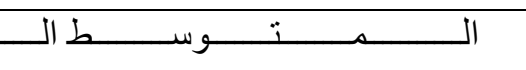 & \\
\hline
\end{tabular}

ك5 = تكرارات* 
توضح النتائج إتفاق عينة الدراسة على أن معوقات السياحة الجيولوجية المرتبطة بالسياسة السياحية الحكومية هى أن جهود التنشيط السياحى تتركز على الأنماط السياحية الثاطئية بمتوسط حسابي (4.46) وعدم وجود استراتيجية لتشجيع الاستثار في أنماط سياحية مستحدثة بجانب السياحة الجماعية " بمتوسط حسابي (4.41), وكذلك تعارض وجن المصالح بين الجهتين المسؤولين عن المحمية الطبيعية وهما قطاع المحميات الطبيعية وهيئة التتمية السياحية)" بمتوسط حسابي (4.46) و تعارض القوانين المنظمة لأعمال المناجم والمحاجر والتعدين مع تلك المرتبطة بالنشاط السياحي " بمتوسط حسابي (4.35) و قصور البرامج الإعلامية المناسبة للتعريف بالتراث الجيولوجى في محمية وادى الجمال " بمتوسط حسابي (4.30),

4-محور المعوقات الخاصة بمنظمى البرامج السياحية الدولية يهدف هذا المحور لمعرفة المعوقات الخاصة بمنظمى البرامج السياحية الدولية جدول (6) إجابات يوضح إجابات الزائرين على عبارات هذا المحور علي النحو التالي: جدول (6) المعوقات الخاصة بمنظمي الرحلات السياحية الدولية

\begin{tabular}{|c|c|c|c|c|c|c|c|c|c|c|}
\hline \multirow[t]{2}{*}{ الترتيب } & \multicolumn{2}{|c|}{ المؤشرات الإحصائية } & \multicolumn{5}{|c|}{ درجة التكرار والنسبة المئوية } & \multirow{2}{*}{\multicolumn{2}{|c|}{ العـــــــــــــــارة }} & \multirow[b]{2}{*}{ م } \\
\hline & الانعراف & 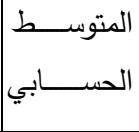 & بثدة & موافق & محايد & 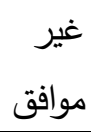 & |بثدة موافق & & & \\
\hline \multirow[t]{2}{*}{2} & \multirow[t]{2}{*}{.750} & \multirow[t]{2}{*}{4.22} & 14 & 18 & 4 & 1 & 0 & ك & \multirow{2}{*}{ 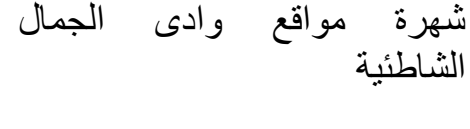 } & \\
\hline & & & 37.8 & 48.6 & 10.8 & 2.7 & 0 & $\%$ & & 1 \\
\hline \multirow[t]{2}{*}{1} & \multirow[t]{2}{*}{.676} & \multirow[t]{2}{*}{4.35} & 17 & 16 & 4 & 0 & 0 & ك) & \multirow{2}{*}{ 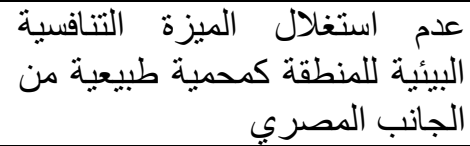 } & \multirow[b]{2}{*}{2} \\
\hline & & & 45.9 & 43.2 & 10.8 & 0 & 0 & $\%$ & & \\
\hline \multirow[t]{2}{*}{4} & \multirow[t]{2}{*}{.834} & \multirow[t]{2}{*}{4.16} & 13 & 19 & 4 & 0 & 1 & ك & \multirow{2}{*}{ السهولة النياحية التسويق $\quad$ للمنتجعات } & \multirow[b]{2}{*}{3} \\
\hline & & & 35.1 & 51.4 & 10.8 & 0 & 2.7 & $\%$ & & \\
\hline \multirow[t]{2}{*}{5} & \multirow[t]{2}{*}{.782} & \multirow[t]{2}{*}{4.00} & 9 & 21 & 5 & 2 & 0 & كs & \multirow{2}{*}{ الأمنية اللازمة بخصوص للبر امج الإجراءية اتبية } & \\
\hline & & & 24.3 & 56.8 & 13.5 & 5.4 & 0 & $\%$ & & 4 \\
\hline \multirow[t]{2}{*}{3} & \multirow[t]{2}{*}{.800} & \multirow[t]{2}{*}{4.16} & 14 & 16 & 6 & 1 & 0 & ك & \multirow{2}{*}{ 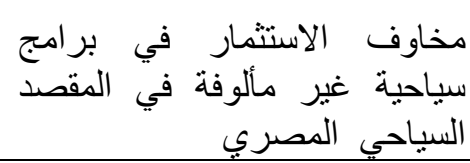 } & \\
\hline & & & 37.8 & 43.2 & 16.2 & 2.7 & 0 & $\%$ & & 5 \\
\hline- & 0.768 & 4.18 & & & & & & & 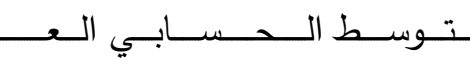 & \\
\hline
\end{tabular}

=ك =كرارات

توضح النتائج إتفاق العينة على المعوقات الخاصة بمنظمى البرامج الساحية الدوليين تتمثل فى عدم استغلال الميزة التنافسية البيئية للمنطقة كمحية طبيعية من الجانب المصري بالمرتبة الأولي من حيث موافقة أفراد عينة الدراسة عليها بمتوسط حسابي (4.35) وشهرة مواقع وادى الجمال الثاطئية " بمتوسط حسابي (4.22)، 


\section{5-محور المعوقات التنظيمية}

يهدف هذا المحور لمعرفة المعوقات التظظيمية بالمحمية عينة الدراسة. جدول (7) إجابات يوضح إجابات الزائرين على عبارات هذا المحور على النحو التالي:

جدول (7) المعوقات التنظيمية

\begin{tabular}{|c|c|c|c|c|c|c|c|c|c|c|}
\hline \multirow[t]{2}{*}{ 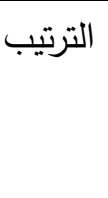 } & \multicolumn{2}{|c|}{ المؤشرات الإحصائية } & \multicolumn{5}{|c|}{ درجة التكرار والنسبة المئوية } & \multirow{2}{*}{\multicolumn{2}{|c|}{ 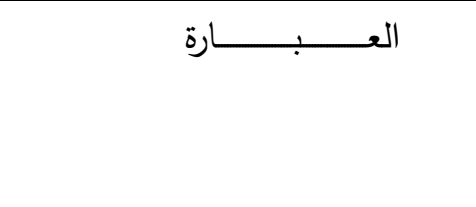 }} & \\
\hline & الالانحراف & الدتوبــي & 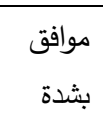 & 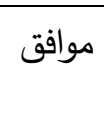 & محايد & غوافق & بثدة موافق & & & \\
\hline \multirow[t]{2}{*}{1} & \multirow[t]{2}{*}{.702} & \multirow[t]{2}{*}{4.30} & 15 & 19 & 2 & 1 & 0 & 5 & \multirow{2}{*}{ التصعاريح الأمنية والمول افقات على } & \\
\hline & & & 40.5 & 51.4 & 5.4 & 2.7 & 0 & $\%$ & & 1 \\
\hline \multirow[t]{2}{*}{2} & \multirow[t]{2}{*}{.776} & \multirow[t]{2}{*}{4.19} & 14 & 17 & 5 & 1 & 0 & 5 & \multirow{2}{*}{ 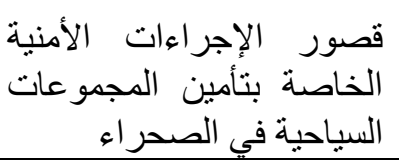 } & \\
\hline & & & 37.8 & 45.9 & 13.5 & 2.7 & 0 & $\%$ & & 2 \\
\hline \multirow[t]{2}{*}{3} & \multirow[t]{2}{*}{.737} & \multirow[t]{2}{*}{4.11} & 9 & 25 & 2 & 0 & 1 & ك & \multirow{2}{*}{ الأمحمية من قالمبل الجهات } & \\
\hline & & & 24.3 & 67.6 & 5.4 & 0 & 2.7 & $\%$ & & 3 \\
\hline- & 0.738 & 4.20 & \multicolumn{8}{|c|}{ الـــــــــــوســــ الــــــــــــــــــــــــام } \\
\hline
\end{tabular}

يتضح من النتائج أن أفراد عينة الدراسة يوافقوا على أن صعوبة الحصول على التصاريح الأمنية والموافقات تشكل أهم الصعوبات التنظيمية وذلك بمتوسط حسابي (4.30). رابعا: اختبار فروض الاراسة جدول (8) نتائج الانحدار المتعدد للعلاقة بين المحاور المستقلة والدحور التابع.

\begin{tabular}{|r|r|r|r|r|r|}
\hline \multicolumn{2}{|c|}{ معيnnn} \\
\hline
\end{tabular}

يوضح الجدول السابق مدي تاثير الدتغيرات المستقلة (معوقات خاصة بالمواقع الجيولوجية - معوقات خاصة بالسياسة السياحية الحكومية - معوقات خاصة بمنظمى البرامج السياحية الدولية - معوقات تنظيمية) , علي المتغير 
التابع مما يؤكد على قبول الفرضية أنه يوجد تأثير معنوي ذو دلالة إحصائية عند مستوي معنوية (0.05) لمعوقات السياحة الجيولوجية في منطقة محمية وادى الجمال علي الوضع الراهن للطلب السياحي على برامج السياحة الجيولوجية في المحمية

3-

أشارت النتائج إلى أن أهم التحديات أمام تطوير السياحة الجيولوجية فى وادي الجمال هي قصور البنية التحتية

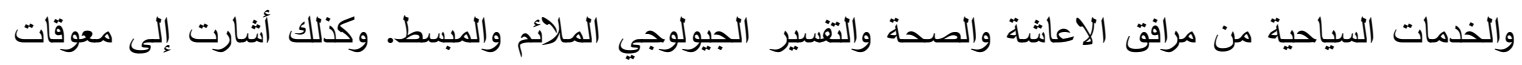

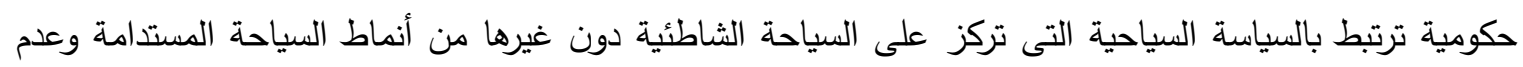
تشجيع الإستثمار فى تلك الأنماط السياحية وعم إستغلال الميزة التتافسية للمحميات الطبيعية وقصور البرامئه الإعلامية بالاضافة الى مخاوف منظمى البرامج الدوليين من الاستثمار فى أنماط سياحية جديدة فى مصر .

4-التوصيات

تعتبر المواقع الجيولوجية فى منطقة الدراسة هى عوامل جذب سياحى محتملة، وتحتاج إلى المزيد من التتمية السياحية لتحسين البنية الأساسية للسياحة الجيولوجية فى وادي الجمال، وهى فرصة حقيقية لتويع المنتج السياحى

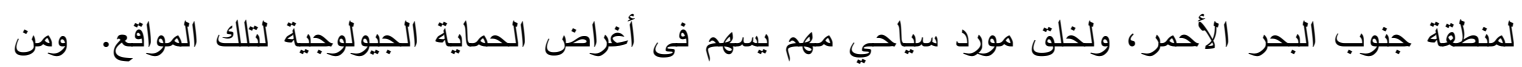
التوصيات التى تساعد على تحقيق ذلك الهدف.

- توصيات موجهة إلى قطاع المحميات الطبيعية (وزارة البيئة)

دعوة مراكز الأبحاث والجامعات المصرية والعالمية للبحث والدراسة فى التراث الجيولوجي لمحمية وادي الجمال مما يسهم فى زيادة المعرفة العلمية حول المواقع الجيولوجية ويوفر قدراً من الاهتمام بحماية ذلك التراث. توفير وسائل الشرح وتفسير المواقع والعمليات الجيولوجية باستخدام اللوحات الإرشادية المصنوعة من الخامات البيئية كالأحجار والأخشاب. وكذلك اعداد وسائل التفسير بثكل أكثر فاعلية وامتاعا مثل الخرائط التفاعلية والمسارات الافتراضية والكتيبات.

تطوير مسارات دخول المواقع الجيولوجية بشكل سليم وعمل ممرات حول تلك المواقع تسهل عمل الجولات السياحية. مع تدعيم الخدمات التنسيرية المناسبة والمرافق السياحية.

يجب أن تقدم ادارة المحمية دورات تدريبية لمتحدثى اللغات المختلفة حول التراث الجيولوجي للمحمية بهدف إعداد مرشد بيئي لتوفير المرشدين السياحيين.

التتسيق مع وزارة التعدين لتحديد اماكن التنقيب عن المعادن بعيدا عن المواقع الحساسة بيئيا ومواقع التراث التقافى، وضمان ن عمليات التتقيب لن تتسبب فى اثار سابية على الموارد الطبيعية والثقافية للمحمية. ضرورة توفير مستويات مرتفعة من السلامة وتاكيد الممارسات الامنة وامكانية الوصول بسهولة الى المرافق الطبية حال الحاجة اليها. 


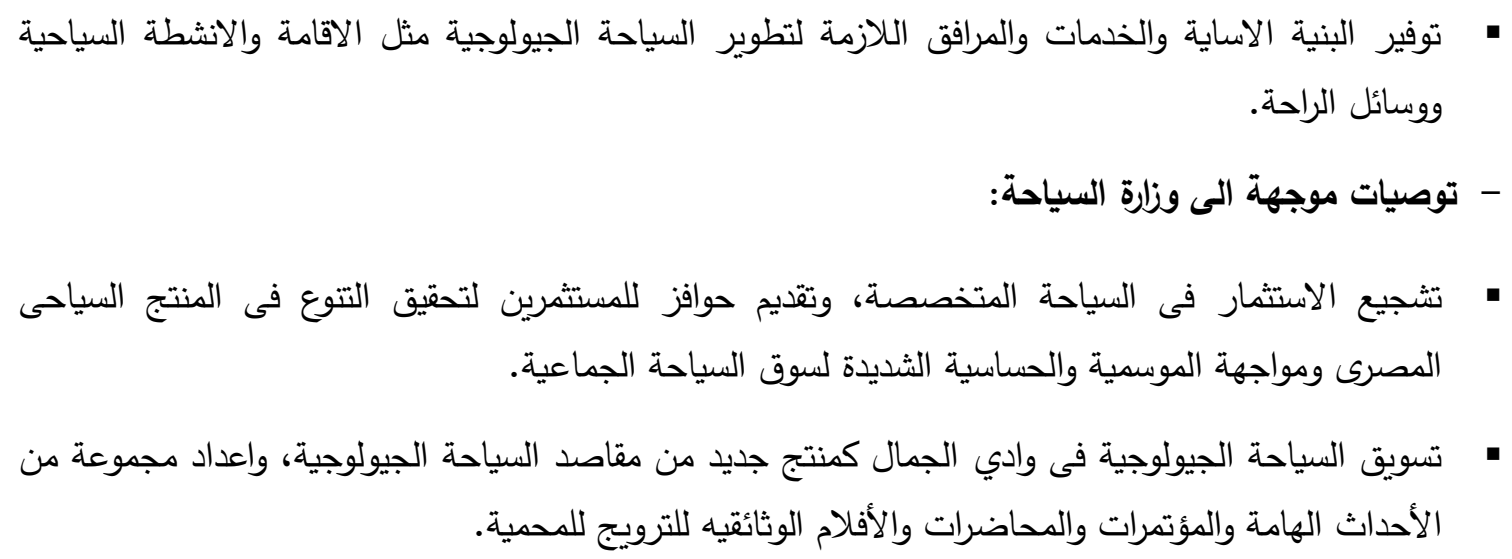

Allan, M.(2013).Geotourism: the potential of geotourism development in the United Arab of Emirates.Second International Conference on Emerging Research Paradigms in Business and Social Sciences. Dubai: Middlesex University Dubai.

Baha-Eddin,S.(2003).Management Plan for Wadi El-Gemal-Hamata.U.S.Agency for International Development Program Support Unit.Cairo: Egyptian Environmental Policy Program.

Dowling, R.(2009).Geotourism's contribution to Local and Regional Development.In N.d.Carvalho,\& J.C.Rodrigues, Geotourism\& Local Development (pp.1537).Idanha-a-Nova, 15-37.

Ehsan, S., Leman, M.S.,\& Ara Begum, R.(2013).Geotourism: A Tool for Sustainable Development of Geoheritage.Advanced Materials Research, 622, 1711-1715.

El-Rahmany, M.M., Saleh, G.M., El-Desoky, H.M.,\& El-Awny, H.M.(2015).Wadi ElGemal Tourmaline-Bearing Deposits, Southern Eastern Desert, Egypt: Constraints on Petrology and Geochemistry.International Journal of Scientific Engineering and Applied Science (IJSEAS), 1 (8).

El-Regal, M.A.(2014).Impact of the valley flooding upon the abundance and diversity of the reef fishes in Wadi El-Gemal protected area, Red Sea, Egypt.Egyptian Journal of Aquatic Biology and Fisheries, 287(1829), 1-26., 18 (1), 83-95.

Farsani, N.T., Coelho, C.,\& Costa, C.(2012).Geotourism and Geoparks as Gateways to Socio-cultural Sustainability in Qeshm Rural Areas, Iran.Asia Pacific Journal of Tourism Research, 17, 30-48.

Farsani, N., Coehlo, C.,\& Costa, C.(2012).Tourism crisis management in geoparks through geotourism development.Revista Turismo\& Desenvolvimento, 3 (17), 1627-1638.

Gordon, J.E.(2018).Geoheritage, Geotourism and the Cultural Landscape: Enhancing the Visitor Experience and Promoting Geoconservation.Geosciences, 8.

Harrell, J.A.(2004).Archaeological Geology of the World's First Emerald Mine.Geoscience Canada, 31 (2). 
Hose, T.(1995).Selling the story of Britain's stone.Environmental interpretation, 10, 1617.

Hose, T.(2006).Geotourism and interpretation.In R.K.Dowling,\& D.Newsome, Geotourism, sustainability, impacts and management (pp.221-241).Elsevier Ltd.

Hose, T.A.(2011).The English Origins of Geotourism (as a Vehicle for Geoconservation) and Their Relevance to Current Studies.Acta geographica Slovenica, 51, 343-360.

Hose, T.A.(2012).3G's for Modern Geotourism.Geoheritage, 4, 7-24.

Hose, T.(2016).Appreciating Physical Landscapes: Three Hundred Years of Geotourism.London: The Geological Society.

Hose, T.,\& Dowling, R.(2006).Geotourism and interpretation.In D.Newsome, Geotourism, sustainability impacts and Management (pp.221-241).Elsevier Ltd.

Kamel, M.Y., Hassan, S.B.,\& Wafik, G.M.(2018).The Challenges of Geotourism in Egypt: A Case Study of Wadi Al-Hitan.International Journal of Hospitality\& Tourism Systems, 10 (2), 32-46.

Madkour, H.A.(2005).Geochemical and environmental studies of recent marine sediments and some hard corals of Wadi El-Gemal area of the Red Sea, Egypt..Egyptian Journal of Aquatic Research, 31 (1), 69-91.

Mahmoud, M.A.(2013).A preliminary study of graphite-bearing rocks at Wadi Sikait area, South Eastern Desert, Egypt.Arab J Geosci, 6, 4661-4669.

Mansour, A.M.(2003).Mining, Quarrying, Geology\& Minerals at Wadi El GemalHamata Protected Areas.U.S.Agency for International Development, MOBIS Task Order No.263-M-00-03-00002-00.

National Geographic Society(2009).Programs for Places.Retrieved from National Geographic Center for Sustainable Destinations: http: //www.nationalgeographic.com/ travel/sustainable/programs_for_places.html\#where-we-do-it

Newsome, D.,\& Johnson, C.P.(2013).Potential Geotourism and the Prospect of Raising Awareness About Geoheritage and Environment on Mauritius.Geoheritage, 5, 19.

Ólafsdóttir, R.,\& Tverijonaite, E.(2018).Geotourism: A Systematic Literature Review, Geoscience ,8(7).

Samy, M., Lizaso, J.L.,\& Forcada, A.(2011).Status of marine protected areas in Egypt.Animal Biodiversity and Conservation, 34 (1).

Sarhan, M.(2016).Public Private Partnership for Ecotourism Development in Wadi el Gemal National Park in Egypt.Retrieved 5 4, 2019, from www.iucn.org: https: //www.iucn.org/news/commission-environmental-economic-and-socialpolicy/201608/public-private-partnership-ecotourism-development-wadi-elgemal-national-park-egypt.

Tourism Development Authority(2003).Land Use Management Plan.South Mersa Alam, Red Sea Coast, Egypt.Red Sea Sustainable Tourism Initiative.Cairo: Tourism Development Authority. 


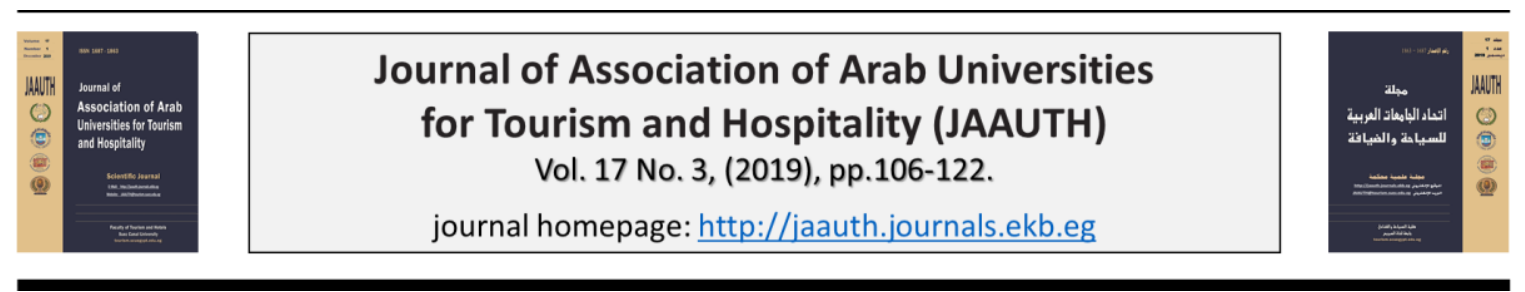

Obstacles of Geotourism in Egypt as applied to Wadi El Gemal National Park

Ahmed Tawfik Soad Omran

Tourism Studies Department, Faculty of Tourism and Hotels, Suez Canal University

\section{ARTICLE INFO}

Keywords:

Geo-tourism; Wadi El

Gemal; National Park.

(JAAUTH)

Vol. 17, No. 3, (2019),

PP. 106-122.

\section{Abstract}

This research aims to explore the obstacles of Geotourism in Wadi El Gemal National Park as a potential model for Geotourism in Egypt. The research relied on the descriptive approach to describe and analyze the phenomenon, and it relied on collecting primary data on survey forms that were directed to the managers of tourism companies in the region of the South Red Sea. The importance of research emerges in providing a vision for Geo-tourism development by exploring the obstacles that prevent developing Geo-tourism activities in the study area. The research pointed to obstacles related to several axes, including organizational obstacles, obstacles related to government tourism policy, and obstacles related to international tour operators. 